\title{
A temporal-specific and transient cAMP increase characterizes odorant classical conditioning
}

\author{
Wen Cui, ${ }^{1}$ Andrew Smith, ${ }^{1}$ Andrea Darby-King, ${ }^{1}$ Carolyn W. Harley, ${ }^{2}$ \\ and John H. McLean ${ }^{1,3}$ \\ ${ }^{1}$ Division of Basic Sciences, Faculty of Medicine, Memorial University of Newfoundland, St. John's, Newfoundland, A1B 3V6, \\ Canada; ${ }^{2}$ Department of Psychology, Faculty of Science, Memorial University of Newfoundland, St. John's, \\ Newfoundland, A1B 3X9, Canada
}

\begin{abstract}
Increases in cyclic adenosine monophosphate (cAMP) are proposed to initiate learning in a wide variety of species. Here, we measure changes in CAMP in the olfactory bulb prior to, during, and following a classically conditioned odor preference trial in rat pups. Measurements were taken up to the point of maximal CREB phosphorylation in olfactory bulb mitral cells. Using both drug and natural unconditioned stimuli we found effective learning was associated with an increase in cAMP at the end of the conditioning trial, followed by a decrease 5 min later. This early timing of a transient cAMP increase occurred only when the odor was paired with an effective drug or natural unconditioned stimulus (US). The data support the hypothesis that the rate of adenylate cyclase activation is enhanced by pairing calcium and G-protein activation and that the timing of transient cAMP signaling is critical to the initiation of classical conditioning.
\end{abstract}

An increase in cyclic adenosine monophosphate (cAMP) was first implicated as a critical intracellular signal for short-term and long-term behavioral adaptation in the Aplysia sensitization model (Brunelli et al. 1976). Since the work in Aplysia, experiments in Drosophila (Byers et al. 1981; Inoue and Yoshioka 1997) and rodents (Bourtchuladze et al. 1994, 1998, 2003; Yuan et al. 2003b) have suggested that cAMP is an evolutionarily conserved messenger for the initiation of associative learning. Manipulations of the cAMP cascade support the inference that increases in cAMP initiate learning. However, apart from work in Aplysia, experimenters have not measured cAMP increases during learning acquisition.

In extending the sensitization model to classical conditioning, it was proposed that calcium-sensitive adenylate cyclase (AC) would mediate the temporal requirements of classical conditioning. The rate of AC activation was enhanced in neuronal membranes from Aplysia, Drosophila, and rodents when calcium pulses (activated by a hypothetical conditioned stimulus or CS) preceded monoamine activation of G-proteins (activated by a hypothetical unconditioned stimulus or US), while AC activation was inhibited by backward pairing (US precedes CS) (Yovell and Abrams 1992). In these experiments, the rate of activation of AC was more sensitive than the absolute levels of cAMP generated, although small differences in peak cAMP levels were seen with the forward pairing (CS precedes US) of calcium and a monoamine. Bourne and Nicoll (1993) later raised the question of whether the level of cAMP or the spatiotemporal pattern of cAMP was the critical factor initiating the neural circuitry changes that support conditioning.

The present experiments measure the temporal pattern of cAMP increases in the olfactory bulb during acquisition of a classically conditioned odor preference that requires activation of the olfactory bulb cAMP cascade. Using three methods of induc-

\section{${ }^{3}$ Corresponding author.}

E-mail mclean@mun.ca; fax (709) 777-7010.

Article is online at http://www.learnmem.org/cgi/doi/10.1101/lm.496007. ing an effective US for classical conditioning, we demonstrate that a temporally specific, transient increase in cAMP is associated with successful learning, while equivalent, or larger, cAMP increases exhibiting other temporal patterns are not associated with odor preference acquisition. The earlier timing of conditioning-associated cAMP increases, when natural stimuli are used as the US, suggests that rate of AC activation is a critical contributor to CS-US pairing effects. The transient profile of successful CS-US pairings when pharmacological stimuli are used argues both an increase and a decrease in cAMP are important for initiating associative learning. Sustained increases were ineffective in inducing learning. In these experiments, the increases in cAMP predominate in the mitral/tufted cells of the olfactory bulb, consistent with other evidence that CS-US pairing modifies mitral/ tufted cell circuitry (Yuan et al. 2003b) and consistent with our hypothesis that intramitral cell signaling cascades involving AC and G-protein-coupled adrenoceptors are critical in learning (McLean and Harley 2004).

Rat pup odor preference learning is a highly adaptive form of learning for organisms that need to remain near their mother for care in the first week of life but which have limited auditory and visual capacities. A 10-min pairing of a novel odor and elements simulating maternal care, such as tactile stimulating (stroking) or milk produces a preference for the novel odor that can be measured $24 \mathrm{~h}$ later (Sullivan and Hall 1988). Multiple pairings can produce a lifelong preference for the same odor that is manifest in sexual (Fillion and Blass 1986) or maternal choices in adult animals (Shah et al. 2002). The stroking US has been shown to activate the noradrenergic neurons of the locus coeruleus (Nakamura et al. 1987), and stroking elevates olfactory bulb norepinephrine (Rangel and Leon 1995). We have shown that $\beta 1$-adrenoceptor activation paired with odor can produce the same odor preference learning as natural stimuli (Harley et al. 2006). Earlier work demonstrated that the $\beta$-adrenoceptor agonist, isoproterenol, delivered at an optimal dose systemically (Sullivan et al. 1989), or in the olfactory bulb itself (Sullivan et al. 2000), produces odor preference learning. Thus, the critical sub- 
strate for odor preference learning is in the olfactory bulb, and $\beta 1$-adrenoceptor activation is sufficient to induce learning. Olfactory bulb $\beta$-adrenoceptor activation is also necessary for learning with natural stimuli, such as stroking, since $\beta$-adrenoceptor blockade locally in the olfactory bulb prevents stroking-induced odor preference learning (Sullivan et al. 1991).

Previously, we proposed a model of odor preference learning in which odor input (CS) and $\beta$-adrenoceptor activation (US) converge on olfactory bulb mitral cells to initiate cellular changes (Yuan et al. 2003b). Odor activation of glutamate receptors (Ennis et al. 1998; Yuan et al. 2000) and calcium entry would interact with US activation of $\beta$-adrenoceptors and AC to elevate cAMP in odor-encoding mitral cells. Elevated cAMP activates PKA to phosphorylate cAMP response element binding protein (CREB) to induce learning-related structural changes. The cAMP/PKA/CREB cascade has been causally implicated in odor preference learning (McLean et al. 2005). Phosphodiesterase 4 (PDE4) inhibitors that prevent cAMP breakdown permit effective learning with a suboptimal dose of isoproterenol (McLean et al. 2005). Viral manipulations of CREB reveal that CREB phosphorylation, which is maximal 10 min following a 10-min conditioning trial, is also causal in odor preference learning, with a negative dominant form of CREB infused in the olfactory bulb mitral cell layer preventing learning (Yuan et al. 2003a). Mitral/tufted cells are proposed as a convergence site for $\beta 1$-adrenoceptors and odormediating glutamate receptors (Yuan et al. 2003b).

The $\beta$-adrenoceptor agonist, isoproterenol, is only effective as a US in a narrow dosage window. Two $\mathrm{mg} / \mathrm{kg}$ is an effective US, while $1 \mathrm{mg} / \mathrm{kg}$ is ineffective, as are 4 or $6 \mathrm{mg} / \mathrm{kg}$ (Sullivan et al. 1991; Langdon et al. 1997). Previously, we measured the levels of olfactory bulb cAMP at the end of the 10-min conditioning period, predicting that cAMP levels would differ among effective and ineffective doses of isoproterenol (Yuan et al. 2003b). While cAMP levels induced by using $1 \mathrm{mg} / \mathrm{kg}$ isoproterenol as a US did not differ from those of saline, the level induced by $2 \mathrm{mg} / \mathrm{kg}$ was significantly higher, as predicted by a cAMP-mediation model; however, $4 \mathrm{mg} / \mathrm{kg}$, an ineffective US, produced a level of cAMP increase similar to that induced by $2 \mathrm{mg} / \mathrm{kg}$. Thus, level of cAMP could not predict learning versus nonlearning when observed at the time point immediately after training.

Here, in the first set of experiments, we examine the temporal pattern of cAMP during and after the conditioning period to ask if other time points differentiate learning and nonlearning conditions. We measure levels of cAMP in the olfactory bulb at 5-min intervals in separate cohorts given odor and a pharmacologically induced US pairing from just prior to the onset of the CS-US pairing until the time of maximal CREB phosphorylation 10 min following CS-US pairing. The results suggest that an increase in cAMP at the end of the conditioning interval followed by a decrease in cAMP 5 min later is uniquely associated with learning. A sustained increase in cAMP over the same time interval was associated with failure to learn.

In the second set of experiments, we make the same measurements in a natural learning paradigm with stroking as the US. The timing and pattern of cAMP increase and decrease associated with the CS-US pairing is the same as that seen for the effective isoproterenol US. However, unlike the drug experiments, all natural stimuli induce transient increases in cAMP, which differ in their timing. The earliest transient response is seen with CS-US pairing.

In the third set of experiments, we examine a US that combines a PDE4 inhibitor with an ineffective low dose of isoproterenol to induce learning. The same transient increase in cAMP at the end of the conditioning period is observed in this PDE-promoted learning condition as in the previous experiments.

\section{Results}

A transient increase in CAMP at the end of the conditioning trial, followed by a significant decrease within $5 \mathrm{~min}$, is associated with learning, while a sustained increase in cAMP is associated with nonlearning

When measured at 5-min intervals, cAMP increased significantly by the end of the 10-min conditioning period in rat pups treated with $2 \mathrm{mg} / \mathrm{kg}$ isoproterenol and placed over odor (three drugs $\times$ five time points interaction, $\left.F_{(8,101)}=3.64, P<0.009\right)$. At the end of the conditioning period, as in our prior experiments, cAMP was also elevated in the $6 \mathrm{mg} / \mathrm{kg}$ isoproterenol group, which does not show odor preference learning (Fig. 1). Five minutes after the conditioning period, cAMP levels dropped significantly in the $2 \mathrm{mg} / \mathrm{kg}$ isoproterenol learning group and no longer differed from the cAMP level in saline-treated pups. The cAMP level in the $6 \mathrm{mg} / \mathrm{kg}$ isoproterenol group was significantly higher than both the $2 \mathrm{mg} / \mathrm{kg}$ learning group and the salinetreated group at this time point. At the end of sampling, when CREB is normally maximally phosphorylated, cAMP levels were elevated in both the 2 and $6 \mathrm{mg} / \mathrm{kg}$ isoproterenol groups relative to the saline group. Levels in the $6 \mathrm{mg} / \mathrm{kg}$ isoproterenol group were now significantly higher than levels in the $2 \mathrm{mg} / \mathrm{kg}$ group, as well. This suggested an oscillatory pattern might be occurring, but since CREB phosphorylation had already been recruited, these final time points are not likely to be significant for the functional effects of the optimal odor and $2 \mathrm{mg} / \mathrm{kg}$ drug pairing. Pups sacrificed for cAMP immunohistochemistry at the end of the sampling period, $10 \mathrm{~min}$ after the conditioning trial, showed a cAMP signal in the mitral cell layer consistent with the assay results: The cAMP signal was strongest in the $6 \mathrm{mg} / \mathrm{kg}$ isoproterenol group, followed by the $2 \mathrm{mg} / \mathrm{kg}$ isoproterenol group, and was weakest in the saline group $F_{(2,18)}=15.92, P<0.001$; Fig. 2$)$.

\section{Pairing the CS with the isoproterenol US is critical for the transient increase in CAMP at the end of the conditioning trial}

All rat pups in the initial experiment received odor. A follow-up experiment was designed to replicate the initial results for $2 \mathrm{mg} / \mathrm{kg}$ isoproterenol for the two critical time points, the end of the conditioning period and $5 \mathrm{~min}$ later. Control groups received isoproterenol or saline injections at the same time, but they were

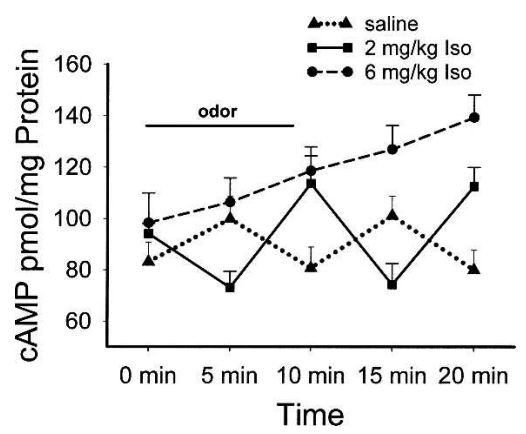

Figure 1. Drug-induced learning shows a transient CAMP increase at the end of training. Odor exposure paired with an optimal unconditioned stimulus ( $2 \mathrm{mg} / \mathrm{kg}$ isoproterenol, Iso) produces CAMP transiently, showing a significant increase at the end of training and a significant decrease 5 min later. Odor paired with saline was associated with variable cAMP levels, but they did not differ significantly from baseline. The supraoptimal, nonlearning, $6 \mathrm{mg} / \mathrm{kg}$ Iso dose paired with odor showed a temporal linear increase in CAMP. Two-way ANOVA $F_{(8,101)}=3.64, P<0.01 . N=7$ or 8 for each point. 

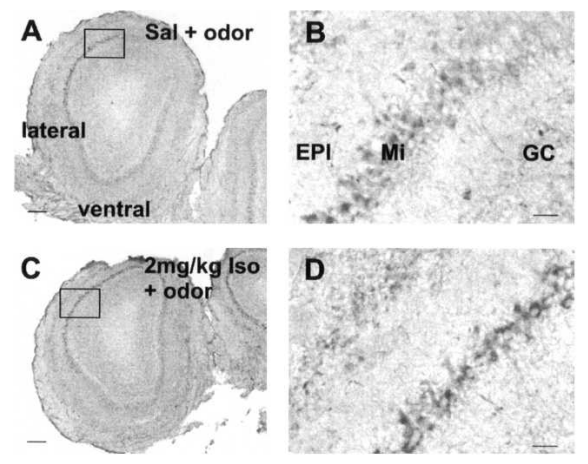

\section{G}

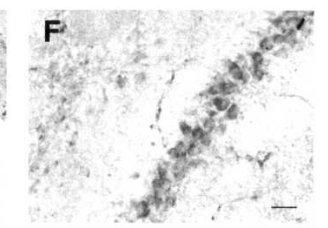

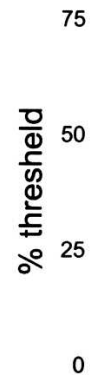

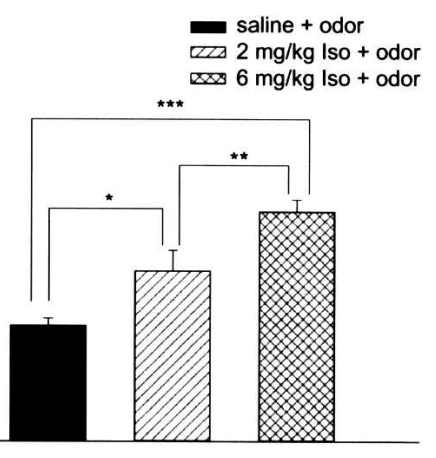

Figure 2. Drug condition correlation of cAMP expression visualized by immunohistochemistry. Immunohistochemical label of cAMP in the olfactory bulbs of pups exposed to peppermint odor paired with either saline $(A, B), 2 \mathrm{mg} / \mathrm{kg}$ Iso $(C, D)$, or $6 \mathrm{mg} / \mathrm{kg}$ Iso $(E, F) .(B, D, F)$ Higher magnifications of regions indicated in $A, C$, and $E$, respectively. CAMP expression was especially evident in mitral cells in $B, D$, and $F$ and tended to increase in density with the higher isoproterenol dose. Scale markers in $A, C$, and $E$ : $200 \mu \mathrm{m}$; in $B, D$, and $F: 25 \mu \mathrm{m}$. (G) The percentage (\%) threshold of cAMP immunohistochemical staining of mitral cells. The $2 \mathrm{mg} / \mathrm{kg}$ Iso + odor group expressed significantly higher cAMP than the saline + odor group. CAMP in the $6 \mathrm{mg} / \mathrm{kg}$ Iso + odor group was significantly higher than either the 2 $\mathrm{mg} / \mathrm{kg}$ Iso + odor group or the saline + odor group. One-way ANOVA $F_{(2,18)}=15.92, P<0.001$. The measurements were obtained from olfactory bulbs of animals sacrificed at 10 min after odor presentation. $N=7$ for each group. (Iso) Isoproterenol, (EPI) external plexiform layer, (Mi) mitral cell layer, (GC) granule cell layer.

placed on the bedding without odor for $10 \mathrm{~min}$. Only olfactory bulbs from pups given the paired odor and $2 \mathrm{mg} / \mathrm{kg}$ isoproterenol showed the pattern of elevated cAMP at the end of the conditioning period followed by a significant decrease 5 min later (three conditions $\times$ two time points interaction, $F_{(2,40)}=6.22$, $P<0.005$; Fig. 3). This pattern replicates the initial experiment (Fig. 1). Pups given $2 \mathrm{mg} / \mathrm{kg}$ isoproterenol, not paired with odor, showed an increase in cAMP relative to the saline group at both time points. Thus, the isoproterenol US alone does not account for the increase followed by decrease pattern seen in the first experiment. In summary, a novel odorant CS must be paired with the US to engage the temporal pattern of a cAMP increase at the end of the conditioning trial followed $5 \mathrm{~min}$ later by a decrease, when isoproterenol is used as the US.

\section{Natural learning is also associated with a temporally specific transient increase in CAMP at the end of the conditioning trial, followed by a decrease 5 min later}

An increase in cAMP at the end of the 10-min conditioning period followed by a significant decrease 5 min later was seen when the odor was paired with 1030 -sec stroking events to induce conditioning (three conditions $\times$ five time points interaction, $F_{(8,102)}=4.67, P<0.0007$; Fig. 4). Stroking alone also induced an increase in cAMP, but it occurred $10 \mathrm{~min}$ after the conditioning period had ended. A follow-up experiment revealed that this stroking-alone-induced increase was transient, since cAMP levels returned to baseline $5 \mathrm{~min}$ later (Fig. 4, inset). Odor alone induced a transient increase in cAMP, which occurred 5 min after the end of the conditioning period. Although the average increase in cAMP was largest in the odor+stroking condition, the differences in absolute level of cAMP increases among the three groups were not significant. Thus, both the natural CS and US engaged a transient increase in cAMP, but only a paired CS+US event pro- duced the early transient increase immediately at the end of the conditioning period. In summary, this transient increase at the end of odor conditioning in olfactory bulb cAMP, seen with odor and a natural US, occurs in the same sample time as that associated with odor paired with a pharmacological US in the first set of experiments. The subsequent decrease in cAMP 5 min later also replicates the effects of pairing an effective pharmacological US with the odor (Fig. 1).

Phosphodiesterase inhibition paired with a suboptimal dose of isoproterenol is an effective US, and when paired with odor induces a temporally specific transient increase in cAMP

In a previous study, we demonstrated that $1 \mathrm{mg} / \mathrm{kg}$ isoproterenol becomes an effective US if combined with the PDE4 inhibitor, cilomilast (McLean et al. 2005). This dose of isoproterenol, when paired with odor only, does not significantly elevate cAMP at the end of the conditioning period, does not produce learning, and does not lead to CREB phosphorylation. Here, we examine the same five temporal samples for cAMP changes in pups receiving odor $+1 \mathrm{mg} / \mathrm{kg}$ isoproterenol $+1 \mathrm{mg} / \mathrm{kg}$ cilomilast (effective US) or pups receiving odor +1 $\mathrm{mg} / \mathrm{kg}$ isoproterenol only (ineffective US). As in the first and second experiments (Figs. 1, 4), an increase in cAMP occurred at the end of the 10 -min conditioning period followed by a decrease 5 min later, when odor was paired with the isoproterenol + cilomilast US (two drugs $\times$ five time points interaction, $F_{(1,48)}=15.68, P<0.0005$; see Fig. 5). Odor paired with $1 \mathrm{mg} / \mathrm{kg}$ isoproterenol alone was not associated with any increase in cAMP relative to baseline.

\section{Discussion}

Acceleration of cAMP production may account for the temporal pattern of cAMP increases in the classical conditioning of odor preference In experiments probing the molecular mechanism underlying classical conditioning, Yovell et al. (1992) used AC in membranes

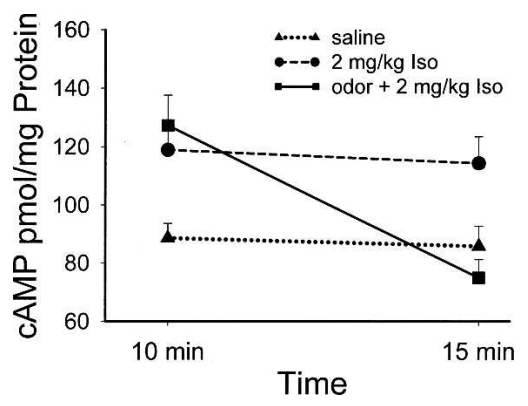

Figure 3. A transient CAMP increase is observed only with the learning condition. Increased, followed by decreased, cAMP at the end of training occurred only when odor was paired with an optimal unconditioned stimulus ( $2 \mathrm{mg} / \mathrm{kg}$ isoproterenol), not with $2 \mathrm{mg} / \mathrm{kg}$ isoproterenol alone or saline alone. Two-way ANOVA, $F_{(2,40)}=6.22, P<0.01$. $N=7-8$ for each point. 


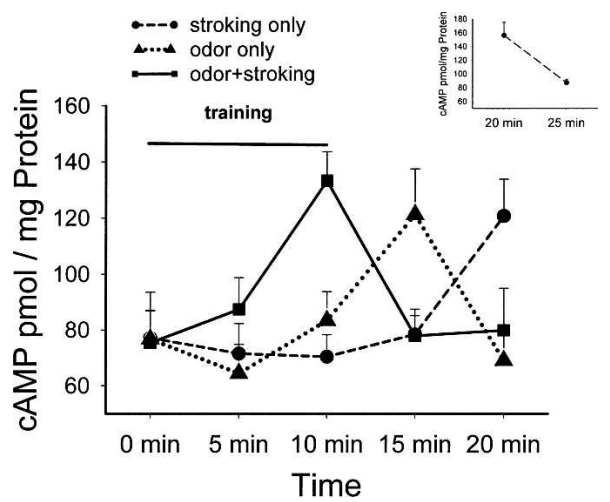

Figure 4. Natural learning shows a transient CAMP increase at the end of the training session. In natural learning (odor + stroking, i.e., tactile stimulation), a transient cAMP increase was seen at the end of training. In the odor-only group and the stroking-only group, a transient CAMP increase occurred $5 \mathrm{~min}$ and $10 \mathrm{~min}$ after the end of training, respectively. Two-way ANOVA, $F_{(8,102)}=4.67, P<0.001 . N=7-8$ for each point.

from rodents, Aplysia, and Drosophila, all of which show cAMPdependent forms of learning. When an 8 -sec pulse of calcium preceded a 6-sec pulse of serotonin, such that some overlap occurred, the rate of the rise of cAMP increased (Yovell and Abrams 1992). The peak of cAMP to serotonin alone and to the 8 -sec calcium pulse paired with serotonin did not differ. They suggested the primary effect of calcium acting through a calcium/ calmodulin complex on AC is to initiate an increase in the rate of cAMP production. Our results, using a novel odorant as the CS and stroking as the US, are consistent with the hypothesis that cAMP production is accelerated by pairing the CS and US. The peak levels of cAMP were only slightly different among the CS (odor) only, US (stroking) only, and CS paired with US conditions. However, the timing differed significantly, with an earlier peak in the CS+US condition. This suggests that when cAMP increases occur relative to other intracellular events is critical for the recruitment of substrate phosphorylation, including, in the present model, CREB (McLean et al. 1999; Yuan et al. 2000), and NMDA (McLean et al. 2003) and AMPA receptors (McLean et al. 2006). Odor alone and stroking alone likely cause changes in the subsequent responsiveness of rat pups, but these changes differ from those recruited to support odor preference memory, and the type of change is likely to relate to the timing of the cAMP pulse.

Another mechanism, in addition to calcium and G-proteins acceleration of AC activation, may contribute to and reinforce an earlier cAMP transient with the pairing of odor and stroking. The pairing of odor and stroking initiates a larger and earlier rise in norepinephrine in the olfactory bulb of rat pups than stroking alone, for which the peak norepinephrine elevation is smaller and delayed (Rangel and Leon 1995). This earlier and larger rise in norepinephrine could be caused locally by the modulation of norepinephrine terminals. Both glutamate (Pittaluga and Raiteri 1992; Raiteri et al. 1992) and GABA (Gervais 1987) enhance norepinephrine release from terminals.

\section{Transient cAMP increases in the olfactory bulb} in association with a natural CS+US and with effective pairings of odor and a pharmacological US are consistent with transient CAMP increases in other neuronal systems

In the present experiments, cAMP elevations to a natural CS and US, whether paired or delivered singly, were confined to a single temporal sample, suggesting a profile of increase and decrease within a 5-min domain. A domain of minutes for cAMP changes is characteristic of other direct cAMP measurements in neurons. In measurements of cAMP in Aplysia abdominal ganglia, cAMP levels were maximal $2 \mathrm{~min}$ after a 5 min serotonin application and declined toward control values by $10 \mathrm{~min}$ (Cedar and Schwartz 1972). The decline occurred even with sustained serotonin application. The authors suggest an intracellular substance antagonizes cAMP synthesis, since a PDE inhibitor increased cAMP but did not prevent decay. In a subsequent paper, $15 \mathrm{~min}$ (Cedar et al. 1972), but not $4 \mathrm{~min}$, of $1-\mathrm{Hz}$ abdominal ganglion nerve stimulation was required to induce a cAMP rise, suggesting effective stimuli require time to elevate cAMP. With stronger stimuli, onset of the cAMP rise can be more rapid in Aplysia bag cell neurons (Kaczmarek et al. 1978). A brief 20-sec tetanic stimulus elicited a prolonged afterdischarge and a peak increase in cAMP 2 min post-stimulus, followed by return to baseline within 4-5 min, although electrical afterdischarges continued. In Aplysia sensory neurons, $5 \mathrm{~min}$ of serotonin exposure produced peak cAMP elevation at the end of the exposure, which declined to baseline in 15 min (Bernier et al. 1982). While these studies, like the present one, used interval sampling, methods that permit continuous cAMP monitoring have been applied in cell systems. Using Fluorescence Resonance Energy Transfer techniques for continual single neuron cAMP visualization in cultured Xenopus spinal cord neurons, spontaneous cAMP transients lasting $3 \mathrm{~min}$ (young cells) to $7 \mathrm{~min}$ (mature cells) are seen (Gorbunova and Spitzer 2002). These cAMP transients depend on calcium transients induced by depolarization and, in turn, enhance the frequency of the calcium transients. In slime mold, 5-min cAMP increase and decrease transients serve both an intra- and extracellular signaling function (Gerisch and Wick 1975; Gerisch et al. 1975).

\section{Transient cAMP patterns underlie the effectiveness of pharmacological USs}

A lack of a significant increase in cAMP accounts for the failure of the low dose of isoproterenol to induce odor preference learning. The occurrence of a significant increase in cAMP at the end of the 10-min conditioning period when a PDE4 inhibitor is given with the low dose of isoproterenol suggests PDE4 is normally recruited prior to that time point and modulates the pattern of cAMP increase. When PDE4 is inhibited, the appropriately timed ACmediated increase in cAMP is expressed. The transient cAMP el-

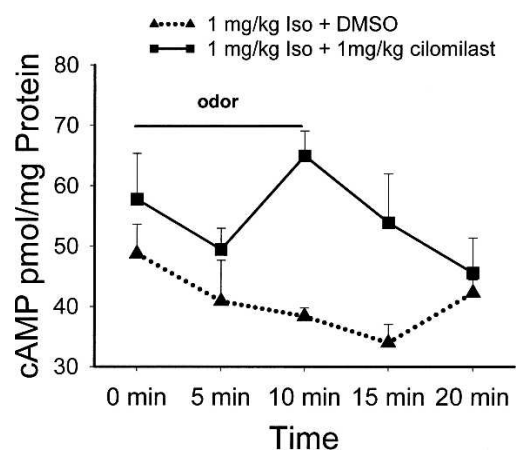

Figure 5. Phosphodiesterase-4-facilitated learning shows a transient CAMP increase at the end of training. When the phosphodiesterase 4 inhibitor, cilomilast, was combined with a suboptimal dose of isoproterenol ( $1 \mathrm{mg} / \mathrm{kg}$ Iso) to produce an effective unconditioned stimulus, with an odor, a transient increase in CAMP was seen at the end of training. Odor paired with $1 \mathrm{mg} / \mathrm{kg}$ isoproterenol alone did not increase the CAMP level. Two-way ANOVA, $F_{(1,48)}=15.68, P<0.001 . N=5-6$ for each point. 
evation at the end of the conditioning interval allows learning to occur.

A sustained rising pattern of cAMP increase is associated with the high dose of isoproterenol. In this instance it may be assumed that cAMP-mediated signals are occurring but differ in their consequences, e.g., absence of CREB phosphorylation 10 min after training (McLean et al. 1999; Yuan et al. 2000) and absence of learning $24 \mathrm{~h}$ later (Sullivan and Wilson 1991; Langdon et al. 1997), due to the anomalous temporal pattern. Recent observations in our laboratory suggest a phosphatase inhibitor given in concert with the high dose of isoproterenol will prolong phosphorylation of targets and produce odor preference learning (Christie-Fougere et al. 2006). This argues that the normal phosphorylation/dephosphorylation balance is altered when a sustained pattern of intracellular cAMP signaling occurs in the mitral cells.

Earlier studies also suggest natural and pharmacological US events engage the same intracellular pathways since two subthreshold US events, one natural and one pharmacological, are additive and become effective, while two optimal events, one natural and one pharmacological, are also additive and become ineffective (Sullivan et al. 1991), showing the same inverted U curve profile reported here for isoproterenol.

\section{Multiple adenylate cyclases may be engaged to induce the temporal variety of cAMP profiles observed in the olfactory bulb}

The olfactory bulb mitral cell ACs have been surveyed (Visel et al. 2006). AC1, which is synergistically activated by calcium and monoamine activation and is a favorite candidate for coincidence detection of the CS+US in other systems (Wayman et al. 1994), does not occur in mitral cells. AC8 is calcium-sensitive and present in mitral cells. AC8, however, appears to be exclusively activated by calcium and does not show synergy with G-proteins activation (Nielsen et al. 1996; Ferguson and Storm 2004). AC3 is present in mitral cells, is activated by isoproterenol, and can be modulated by calcium both as an activator and an inhibitor (Anholt 1994; Wayman et al. 1995). AC2 is modulated by the cooccurrence of GABA B and $\beta$-adrenoceptor activation (Robichon et al. 2004) and could play a role in the cAMP rise in mitral cells, which receive GABAergic lateral and feedback inhibition when activated (Rall et al. 1966; Rall and Shepherd 1968; Shepherd 1972). Finally, AC9 is strongly present in mitral cells and also mediates interactions between calcium and isoproterenol, with both calcium inhibition (Antoni et al. 1998) and activation (Cumbay and Watts 2005) reported.

cAMP increases produced by odor alone seem most likely to relate to activation of calcium-sensitive AC8, since odor did not increase norepinephrine in the olfactory bulb (Rangel and Leon 1995). The delay in cAMP elevation with stroking alone may relate to an absence of calcium entry when only norepinephrine is increased (Yuan et al. 2004) and the consequent lack of AC acceleration, as well as to the temporal profile of a weaker and more delayed rise in olfactory bulb norepinephrine with stroking alone (Rangel and Leon 1995).

The failure to see a transient cAMP pattern with the $2 \mathrm{mg} / \mathrm{kg}$ isoproterenol dose without odor suggests calcium entry plays a role in shaping the transient cAMP profile when drugs are given, possibly through AC3 or AC9 modulation. However, since odor alone and stroking alone also induce transient profiles, a more complex model is required, in which transient cAMP regulation occurs even with distinct modes of engaging cAMP increases. The role of specific ACs in the cAMP patterns observed here will require direct experimental evaluation.

\section{Conclusion}

The present pattern of cAMP modulation during classical conditioning is consistent with the original Yovell and Abrams (1992) proposal that AC acts as a CS+US coincidence detector. In their data from both invertebrates and vertebrates, the rate of rise of cAMP was more strongly modulated than the level of cAMP by the pairing of the CS calcium signal with an overlapping "teaching" signal initiated by G-proteins stimulation. Here, the CS+US induces the earliest cAMP increase observed. The timing of a transient elevation of cAMP in relation to other events in the mitral cell appears critical for recruitment of CREB phosphorylation and 24-h behavioral memory.

\section{Materials and Methods}

\section{Animals}

Sprague-Dawley rat pups of both sexes were used in this study. Litters were culled to 12 pups/litter on postnatal day 1 (PND1; the day of birth is considered PND0). The dams were maintained under a 12-h light/dark cycle, with ad libitum access to food and water. All experimental procedures were approved by the Memorial University Institutional Animal Care Committee. No more than one male and one female pup were used for each condition per litter.

\section{Experimental design}

\section{Drug-induced learning}

For the first set of cAMP measurements, 115 Sprague-Dawley rats, both male and female, from 10 litters were used. Fifteen groups were included: three treatments (odor plus either saline, $2 \mathrm{mg} / \mathrm{kg}$ isoproterenol, or $6 \mathrm{mg} / \mathrm{kg}$ isoproterenol) $\times$ five time points, including the beginning of a 10-min odor-paired training ( $0 \mathrm{~min})$, 5 min after training started (5 min), the end of training (10 min), $5 \mathrm{~min}$ after training ended (15 $\mathrm{min})$, and $10 \mathrm{~min}$ after training ended (20 min).

In the second set of cAMP experiments, 46 Sprague-Dawley rats, both male and female, from four litters were used. Six groups were included: two drug treatments $(2 \mathrm{mg} / \mathrm{kg}$ isoproterenol or saline) $\times$ two time points, including the end of training $(10 \mathrm{~min})$ and 5 min after training ended $(15 \mathrm{~min})+$ two odor conditions (either peppermint or no odor).

In immunohistochemistry, 21 Sprague-Dawley rats, both male and female, from six litters were used. Three treatment groups were included: odor plus saline, $2 \mathrm{mg} / \mathrm{kg}$ isoproterenol, or $6 \mathrm{mg} / \mathrm{kg}$ isoproterenol at $10 \mathrm{~min}$ after training ended (20 min).

\section{Natural learning}

For the first set of cAMP measurements, 117 Sprague-Dawley rats, both male and female, from 15 litters were used. Fifteen groups were included: three conditions (odor only, stroking only, odor + stroking) $\times$ five time points, including the beginning of a 10-min odor-paired training $(0 \mathrm{~min}), 5 \mathrm{~min}$ after training started ( $5 \mathrm{~min}$ ), the end of training (10 $\mathrm{min}), 5 \mathrm{~min}$ after training ended (15 $\mathrm{min})$, and $10 \mathrm{~min}$ after training ended $(20 \mathrm{~min})$.

Forty-five littermates from the 15 litters were tested for odor preference $1 \mathrm{~d}$ after the 10-min training section. See McLean et al. (1996) for the procedure in detail. The percentage of time each pup spent on peppermint-scented bedding over five testing trials was calculated. This littermate condition was used to confirm the effectiveness of the stroking procedure, which shows more variability in outcome than the pharmacological USs.

\section{PDE4 inhibitor-induced learning}

Fifty-eight Sprague-Dawley rats, both male and female, from six litters were used. Ten groups were included: two drug treatments $(1 \mathrm{mg} / \mathrm{kg}$ isoproterenol + DMSO, $1 \mathrm{mg} / \mathrm{kg}$ isoproterenol $+1 \mathrm{mg} /$ $\mathrm{kg}$ cilomilast, cAMP PDE4 inhibitor) $\times$ five time points, includ- 
ing the beginning of a 10-min odor-paired training ( $0 \mathrm{~min}), 5$ min after training started (5 min), the end of training (10 min), 5 min after training ended (15 min), and $10 \mathrm{~min}$ after training ended (20 $\mathrm{min})$.

\section{Injection of drugs/odor conditioning}

\section{Drug-induced learning}

Briefly, on PND6, $50 \mu \mathrm{L}$ of saline (+/ -) isoproterenol (Sigma, 2 $\mathrm{mg} / \mathrm{kg}$ or $6 \mathrm{mg} / \mathrm{kg}$ ) was injected subcutaneously into pups $40 \mathrm{~min}$ before their exposure to odor conditioning.

Rat pups were removed from the dam $10 \mathrm{~min}$ before odor exposure. In the odor only group or odor + drug groups, pups were exposed to the peppermint-scented bedding $(0.3 \mathrm{~mL}$ of peppermint per $500 \mathrm{~mL}$ of fresh bedding) for $10 \mathrm{~min}$. In the drug only groups, pups were placed on fresh bedding for a $10 \mathrm{~min}$ period.

\section{Natural learning}

On PND6, pups were removed from the dam 10 min before odor exposure. In the odor + stroking group, pups were placed on peppermint-scented bedding $(0.3 \mathrm{~mL}$ of peppermint per $500 \mathrm{~mL}$ of fresh bedding) and stroked vigorously on the hind region using a sable brush every other $30 \mathrm{sec}$ for $30 \mathrm{sec}$ over a $10 \mathrm{~min}$ period. In the odor only group, pups were simply exposed to the peppermint scented-bedding for $10 \mathrm{~min}$. In the stroking only group, pups were stroked in the fresh bedding.

The effectiveness of the stroking procedure for these experiments was verified by behavioral testing of littermates $1 \mathrm{~d}$ following training as described earlier. Pups trained with odor + stroking showed a significant odor preference $\left(F_{(2,42)}=34.25, P<0.001\right)$.

\section{PDE4 inhibitor-induced learning}

On PND6, $50 \mu \mathrm{L}(+/-)$ isoproterenol (Sigma, $1 \mathrm{mg} / \mathrm{kg}$ ) was injected subcutaneously into pups $40 \mathrm{~min}$ before their exposure to odor conditioning. After $10 \mathrm{~min}$, i.e., $30 \mathrm{~min}$ before odor exposure, some of the pups were injected subcutaneously with $50 \mu \mathrm{L}$ of either 5\% dimethylsulfoxide (DMSO, Sigma, in saline, vehicle) or a PDE4 inhibitor (cilomilast, a gift from Dr. Greg Rose [Memory Pharmaceuticals, Montvale, NJ], $1 \mathrm{mg} / \mathrm{kg}$ in $5 \%$ DMSO).

Rat pups were removed from the dam 10 min before odor exposure. Both the isoproterenol + DMSO group and the isoproterenol + cilomilast group were exposed to the peppermint-scented bedding $(0.3 \mathrm{~mL}$ of peppermint per $500 \mathrm{~mL}$ of fresh bedding) for $10 \mathrm{~min}$. $28^{\circ} \mathrm{C}$.

All pups were trained and tested in an ambient temperature

\section{Sample collection / cAMP assay}

At different time points, pups in the relevant groups were killed by decapitation. Olfactory bulbs were removed immediately from the skull, frozen on dry ice, and subsequently stored at $-80^{\circ} \mathrm{C}$ in microcentrifuge tubes until they were assayed for cAMP content.

Frozen olfactory bulbs were homogenized in $250 \mu \mathrm{L}$ of $5 \%$ trichloroacetic acid (TCA) on ice using a tissue grinder. Precipitates were removed by centrifuging at $1500 \mathrm{~g}$ for $10 \mathrm{~min}$ at $4^{\circ} \mathrm{C}$. The supernatant solution was transferred carefully to a clean centrifuge tube, while the pellet was kept for protein determination. TCA was extracted from the supernatant with five volumes of water-saturated ether. The residual ether was removed by heating the supernatant for $5 \mathrm{~min}$ to $70^{\circ} \mathrm{C}$. cAMP in the supernatant was measured by using a cAMP enzyme immunoassay kit (Cayman Chemical). The protein pellet was reconstituted by $800 \mu \mathrm{L}$ of $\mathrm{dH}_{2} \mathrm{O}$, and the protein content was assayed by a Bicinchoninic Acid protein assay Kit (Pierce). cAMP content was normalized by protein content in each sample and expressed as $\mathrm{pmol} / \mathrm{mg}$ protein.

\section{Immunohistochemistry}

The olfactory bulbs and brains were immediately removed from the skull vault and immersed in $4 \%$ paraformaldehyde in $0.1 \mathrm{M}$ phosphate buffer for $2 \mathrm{~h}$ at $4^{\circ} \mathrm{C}$. The brains were then placed in a $1 \%$ paraformaldehyde/20\% sucrose mixture overnight. The following day, the brains were transferred into $20 \%$ sucrose in phosphate buffer for $1 \mathrm{~h}$, then quick-frozen in dry ice and cut in the coronal plane at $30 \mu \mathrm{m}$ using a cryostat set at $-20^{\circ} \mathrm{C}$. A series of sections were placed on each slide, so that pairs of bulbs were 120 $\mu \mathrm{m}$ apart.

Immunohistochemical procedures were standard for this laboratory as published previously (McLean et al. 1999, 2001) In brief, a rabbit cAMP antibody (Chemicon International) was diluted $1: 500$ or $1: 1000$ in phosphate buffered saline with $0.2 \%$ Triton X-100, $0.02 \%$ sodium azide, and 1\% normal goat serum and placed on the tissue overnight at $4^{\circ} \mathrm{C}$. Following further incubation using the avidin-biotin complex technique (Vectastain, Vector Labs), the sections were incubated in diaminobenzidine chromogen with $0.01 \% \mathrm{H}_{2} \mathrm{O}_{2}$ for 3-4 min to visualize antigen sites. Sections were then dehydrated and covered using permount and a cover slip. All sections from the same experiment had identical incubation times in the antibodies and identical exposure to chromogen solutions.

\section{Image analysis}

The cAMP staining was analyzed using a Bioquant image analysis system (R\&M Biometrics). Slides were coded so the observer was blind to the experiment. The mitral cell layer was encircled by visualizing sections of the olfactory bulb on a computer screen using a $20 \times$ objective on a Leitz microscope connected to a CCD camera. Light intensity from the microscope was always set at an optical density (OD) of 220. Background correction was performed to provide an even field of illumination. An upper threshold limit was set at 150-180 OD. Thresholds were generally similar from section to section but varied somewhat due to variation in DAB staining between experiments. The percent of threshold for the mitral cell layer was determined by the total number of pixels at or above threshold divided by the total area of sampled mitral cell layer in each field. The mean percentage threshold from all levels in each region was combined as a single measurement for each animal. Regions analyzed included dorsolateral, ventrolateral, ventromedial, and dorsolateral quadrants from the rostral (100-700 $\mu \mathrm{m}$ from the rostral pole), middle (800-1400 $\mu \mathrm{m})$, and caudal (1500-2000 $\mu \mathrm{m})$ olfactory bulb.

\section{Statistical analysis}

A two-way analysis of variance (ANOVA) was used in all cAMP assays to compare drugs or learning conditions by time interaction effects. A one-way ANOVA was used in the OD analysis of immunohistochemistry to compare drug effects. The Least Significant Differences test was used for post hoc comparisons with $P<0.05$.

\section{Acknowledgments}

We thank CIHR (MOP-53761) for financial support awarded to J.H.M. and C.W.H.

\section{References}

Anholt, R.R. 1994. Signal integration in the nervous system: Adenylate cyclases as molecular coincidence detectors. Trends Neurosci. 17: $37-41$.

Antoni, F.A., Palkovits, M., Simpson, J., Smith, S.M., Leitch, A.L., Rosie, R., Fink, G., and Paterson, J.M. 1998. $\mathrm{Ca}^{2+} /$ calcineurin-inhibited adenylyl cyclase, highly abundant in forebrain regions, is important for learning and memory. J. Neurosci. 18: 9650-9661.

Bernier, L., Castellucci, V.F., Kandel, E.R., and Schwartz, J.H. 1982. Facilitatory transmitter causes a selective and prolonged increase in adenosine $3^{\prime}: 5^{\prime}$-monophosphate in sensory neurons mediating the gill and siphon withdrawal reflex in Aplysia. J. Neurosci. 
2: $1682-1691$.

Bourne, H.R. and Nicoll, R. 1993. Molecular machines integrate coincident synaptic signals. Cell 72 (Suppl): 65-75.

Bourtchuladze, R., Frenguelli, B., Blendy, J., Cioffi, D., Schutz, G., and Silva, A.J. 1994. Deficient long-term memory in mice with a targeted mutation of the cAMP-responsive element-binding protein. Cell 79: $59-68$.

Bourtchouladze, R., Abel, T., Berman, N., Gordon, R., Lapidus, K., and Kandel, E.R. 1998. Different training procedures recruit either one or two critical periods for contextual memory consolidation, each of which requires protein synthesis and PKA. Learn. Mem. 5: 365-374.

Bourtchouladze, R., Lidge, R., Catapano, R., Stanley, J., Gossweiler, S., Romashko, D., Scott, R., and Tully, T. 2003. A mouse model of Rubinstein-Taybi syndrome: Defective long-term memory is ameliorated by inhibitors of phosphodiesterase 4. Proc. Natl. Acad. Sci. 100: 10518-10522.

Brunelli, M., Castellucci, V., and Kandel, E.R. 1976. Synaptic facilitation and behavioral sensitization in Aplysia: Possible role of serotonin and cyclic AMP. Science 194: 1178-1181.

Byers, D., Davis, R.L., and Kiger Jr., J.A. 1981. Defect in cyclic AMP phosphodiesterase due to the dunce mutation of learning in Drosophila melanogaster. Nature 289: 79-81.

Cedar, H. and Schwartz, J.H. 1972. Cyclic adenosine monophosphate in the nervous system of Aplysia californica. II. Effect of serotonin and dopamine. J. Gen. Physiol. 60: 570-587.

Cedar, H., Kandel, E.R., and Schwartz, J.H. 1972. Cyclic adenosine monophosphate in the nervous system of Aplysia californica. I. Increased synthesis in response to synaptic stimulation. J. Gen. Physiol. 60: 558-569.

Christie-Fougere, M.M., Darby-King, A., Harley, C.W., and McLean, J.H. 2006. FK-506, a calcineurin inhibitor, prevents the dephosphorylation of cyclic AMP response element binding protein (CREB) and correspondingly prolongs the duration of olfactory memory. Soc. Neurosci. Abstr. 36: 666.4.

Cumbay, M.G. and Watts, V.J. 2005. Gaq potentiation of adenylate cyclase type 9 activity through a $\mathrm{Ca}^{2+} /$ calmodulin-dependent pathway. Biochem. Pharmacol. 69: 1247-1256.

Ennis, M., Linster, C., Aroniadou Anderjaska, V., Ciombor, K., and Shipley, M.T. 1998. Glutamate and synaptic plasticity at mammalian primary olfactory synapses. Ann. N. Y. Acad. Sci. 855: 457-466.

Ferguson, G.D. and Storm, D.R. 2004. Why calcium-stimulated adenylyl cyclases? Physiology 19: 271-276.

Fillion, T.J. and Blass, E.M. 1986. Infantile experience with suckling odors determines adult sexual behavior in male rats. Science 231: 729-731.

Gerisch, G. and Wick, U. 1975. Intracellular oscillations and release of cyclic AMP from Dictyostelium cells. Biochem. Biophys. Res. Commun. 65: $364-370$.

Gerisch, G., Hulser, D., Malchow, D., and Wick, U. 1975. Cell communication by periodic cyclic-AMP pulses. Philos. Trans. R. Soc. Lond. B Biol. Sci. 272: 181-192.

Gervais, R. 1987. Local GABAergic modulation of noradrenaline release in the rat olfactory bulb measured on superfused slices. Brain Res. 400: $151-154$.

Gorbunova, Y.V. and Spitzer, N.C. 2002. Dynamic interactions of cyclic AMP transients and spontaneous $\mathrm{Ca}^{2+}$ spikes. Nature 418: 93-96.

Harley, C.W., Darby-King, A., McCann, J., and McLean, J.H. 2006. $\beta 1$-adrenoceptor or $\alpha 1$-adrenoceptor activation initiates early odor preference learning in rat pups: Support for the mitral cell/cAMP model of odor preference learning. Learn. Mem. 13: 8-13.

Inoue, H. and Yoshioka, T. 1997. Purification of a regulatory subunit of type II cAMP-dependent protein kinase from Drosophila heads. Biochem. Biophys. Res. Commun. 235: 223-226.

Kaczmarek, L.K., Jennings, K., and Strumwasser, F. 1978. Neurotransmitter modulation, phosphodiesterase inhibitor effects, and cyclic AMP correlates of afterdischarge in peptidergic neurites. Proc. Natl. Acad. Sci. 75: 5200-5204.

Langdon, P.E., Harley, C.W., and McLean, J.H. 1997. Increased $\beta$ adrenoceptor activation overcomes conditioned olfactory learning deficits induced by serotonin depletion. Brain Res. Dev. Brain Res. 102: 291-293.

McLean, J.H. and Harley, C.W. 2004. Olfactory learning in the rat pup: A model that may permit visualization of a mammalian memory trace. Neuroreport 15: 1691-1697.

McLean, J.H., Darby-King, A., and Hodge, E. 1996. 5- $\mathrm{HT}_{2}$ receptor involvement in conditioned olfactory learning in the neonate rat pup. Behav. Neurosci. 110: 1426-1434.

McLean, J.H., Harley, C.W., Darby-King, A., and Yuan, Q. 1999. pCREB in the neonate rat olfactory bulb is selectively and transiently increased by odor preference-conditioned training. Learn. Mem. 6: 608-618.

McLean, J.H., Darby-King, A., and Bonnell, W.S. 2001. Neonatal olfactory sensory deprivation decreases BDNF in the olfactory bulb of the rat. Brain Res. Dev. Brain Res. 128: 17-24.

McLean, J.H., Cui, W., Mercer, J., Reid, A., Darby-King, A., and Harley, C.W. 2003. Odor preference learning in neonate rats results in transient phosphorylation of NMDA receptors in the olfactory bulb. Soc. Neurosci. Abstr. 33: 913-916.

McLean, J.H., Darby-King, A., and Harley, C.W. 2005. Potentiation and prolongation of long-term odor memory in neonate rats using a phosphodiesterase inhibitor. Neuroscience 135: 329-334.

McLean, J.H., Cui, W., and Harley, C.W. 2006. PKA phosphorylation of glutamate receptors in the olfactory bulb accompanies memory formation in early odor preference learning in neonatal rats. Soc. Neurosci. Abstr. 36: 666.5 .

Nakamura, S., Kimura, F., and Sakaguchi, T. 1987. Postnatal development of electrical activity in the locus ceruleus. $J$. Neurophysiol. 58: 510-524.

Nielsen, M.D., Chan, G.C., Poser, S.W., and Storm, D.R. 1996. Differential regulation of type I and type VIII $\mathrm{Ca}^{2+}$-stimulated adenylyl cyclases by Gi-coupled receptors in vivo. J. Biol. Chem. 271: 33308-33316.

Pittaluga, A. and Raiteri, M. 1992. N-methyl-D-aspartic acid (NMDA) and non-NMDA receptors regulating hippocampal norepinephrine release. I. Location on axon terminals and pharmacological characterization. J. Pharmacol. Exp. Ther. 260: 232-237.

Raiteri, M., Garrone, B., and Pittaluga, A. 1992. N-methyl-D-aspartic acid (NMDA) and non-NMDA receptors regulating hippocampal norepinephrine release. II. Evidence for functional cooperation and for coexistence on the same axon terminal. J. Pharmacol. Exp. Ther. 260: $238-242$.

Rall, W. and Shepherd, G.M. 1968. Theoretical reconstruction of field potentials and dendrodendritic synaptic interactions in olfactory bulb. J. Neurophysiol. 31: 884-915.

Rall, W., Shepherd, G.M., Reese, T.S., and Brightman, M.W. 1966. Dendrodendritic synaptic pathway for inhibition in the olfactory bulb. Exp. Neurol. 14: 44-56.

Rangel, S. and Leon, M. 1995. Early odor preference training increases olfactory bulb norepinephrine. Brain Res. Dev. Brain Res. 85: $187-191$.

Robichon, A., Tinette, S., Courtial, C., and Pelletier, F. 2004. Simultaneous stimulation of GABA and $\beta$ adrenergic receptors stabilizes isotypes of activated adenylyl cyclase heterocomplex. BMC Cell Biol. 5: 25 .

Shah, A., Oxley, G., Lovic, V., and Fleming, A.S. 2002. Effects of preweaning exposure to novel maternal odors on maternal responsiveness and selectivity in adulthood. Dev. Psychobiol. 41: $187-196$.

Shepherd, G.M. 1972. Synaptic organization of the mammalian olfactory bulb. Physiol. Rev. 52: 864-917.

Sullivan, R.M. and Hall, W.G. 1988. Reinforcers in infancy: Classical conditioning using stroking or intra-oral infusions of milk as UCS. Dev. Psychobiol. 21: 215-223.

Sullivan, R.M. and Wilson, D.A. 1991. The role of norepinephrine in the expression of learned olfactory neurobehavioral responses in infant rats. Psychobiology 19: 308-312.

Sullivan, R.M., Wilson, D.A., and Leon, M. 1989. Norepinephrine and learning-induced plasticity in infant rat olfactory system. J. Neurosci. 9: 3998-4006.

Sullivan, R.M., McGaugh, J.L., and Leon, M. 1991. Norepinephrineinduced plasticity and one-trial olfactory learning in neonatal rats. Brain Res. Dev. Brain Res. 60: 219-228.

Sullivan, R.M., Stackenwalt, G., Nasr, F., Lemon, C., and Wilson, D.A. 2000. Association of an odor with activation of olfactory bulb noradrenergic $\beta$-receptors or locus coeruleus stimulation is sufficient to produce learned approach responses to that odor in neonatal rats. Behav. Neurosci. 114: 957-962.

Visel, A., Varez-Bolado, G., Thaller, C., and Eichele, G. 2006. Comprehensive analysis of the expression patterns of the adenylate cyclase gene family in the developing and adult mouse brain. $J$. Comp. Neurol. 496: 684-697.

Wayman, G.A., Impey, S., Wu, Z., Kindsvogel, W., Prichard, L., and Storm, D.R. 1994. Synergistic activation of the type I adenylyl cyclase by $\mathrm{Ca}^{2+}$ and Gs-coupled receptors in vivo. J. Biol. Chem. 269: 25400-25405.

Wayman, G.A., Impey, S., and Storm, D.R. 1995. $\mathrm{Ca}^{2+}$ inhibition of type III adenylyl cyclase in vivo. J. Biol. Chem. 270: 21480-21486.

Yovell, Y. and Abrams, T.W. 1992. Temporal asymmetry in activation of Aplysia adenylyl cyclase by calcium and transmitter may explain temporal requirements of conditioning. Proc. Natl. Acad. Sci. 89: 6526-6530.

Yovell, Y., Kandel, E.R., Dudai, Y., and Abrams, T.W. 1992. A quantitative study of the $\mathrm{Ca}^{2+} /$ calmodulin sensitivity of adenylyl cyclase in Aplysia, Drosophila, and rat. J. Neurochem. 59: 1736-1744.

\section{Learning \& Memory \\ www.learnmem.org}


Yuan, Q., Harley, C.W., Bruce, A.J., Darby-King, A., and McLean, J.H. 2000. Isoproterenol increases CREB phosphorylation and olfactory nerve- evoked potentials in normal and 5-HT-depleted olfactory bulbs in rat pups only at doses that produce odor preference learning. Learn. Mem. 7: 413-421.

Yuan, Q., Harley, C.W., Darby-King, A., Neve, R.L., and McLean, J.H. 2003a. Early odor preference learning in the rat: Bidirectional effects of cAMP response element-binding protein (CREB) and mutant CREB support a causal role for phosphorylated CREB. J. Neurosci. 23: 4760-4765.

Yuan, Q., Harley, C.W., and McLean, J.H. 2003b. Mitral cell $\beta 1$ and
5- $\mathrm{HT}_{2 \mathrm{~A}}$ receptor colocalization and cAMP coregulation: A new model of norepinephrine-induced learning in the olfactory bulb. Learn. Mem. 10: 5-15.

Yuan, Q., Mutoh, H., Debarbieux, F., and Knopfel, T. 2004. Calcium signaling in mitral cell dendrites of olfactory bulbs of neonatal rats and mice during olfactory nerve stimulation and $\beta$-adrenoceptor activation. Learn. Mem. 11: 406-411.

Received December 5, 2006; accepted in revised form January 9, 2007. 


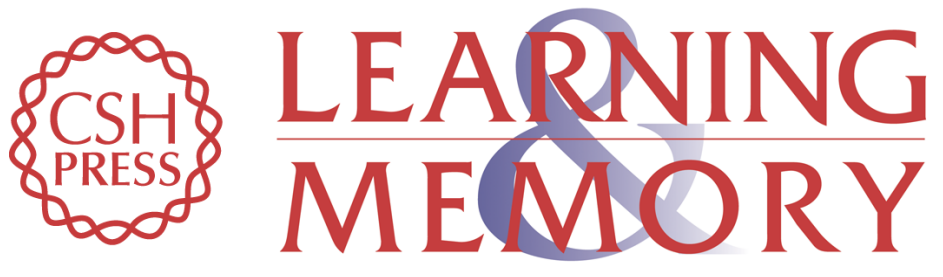

\section{A temporal-specific and transient cAMP increase characterizes odorant classical conditioning}

Wen Cui, Andrew Smith, Andrea Darby-King, et al.

Learn. Mem. 2007, 14:

Access the most recent version at doi:10.1101/lm.496007

References

License

Email Alerting Service
This article cites 55 articles, 22 of which can be accessed free at: http://learnmem.cshlp.org/content/14/3/126.full.html\#ref-list-1

Receive free email alerts when new articles cite this article - sign up in the box at the top right corner of the article or click here. 